\title{
ALKYLATED POLY(4-HYDROXYSTYRENE) DERIVATIVES FOR DEEP ULTRAVIOLET LITHOGRAPHY
}

\author{
D. R. McKean, W. D. Hinsberg, T. P. Sauer, C. G. Willson \\ IBM Research. Almaden Research Center., 650 Harry Road, \\ San Jose, CA 95120-6099
}

\begin{abstract}
Alkylated Poly(4-hydroxystyrene) copolymers have been prepared and evaluated for use in deep-uv lithography. These materials have been modified to lower the dissolution rates of poly(4-hydroxystyrene) while maintaining the other desirable properties such as optical absorbance, glass transition temperature, and etch resistance. Lower dissolution rates make these polymers more attractive for application in dissolution inhibition resist schemes. The application of these materials to resists employing diazo compound inhibitors and thrce component resists using acid photogenerators and acid-sensitive dissolution inhibitors is described.
\end{abstract}

\section{Introduction}

Although current resist materials in combination with advanced exposure tools and processing techniques are adequate for the current generation microelectronic device fabrication, new materials will probably be required for the 0.35 micron geometries necessary for $64 \mathrm{MB}$ DRAM devices. This is due to practical resolution limitations imposed by $365 \mathrm{~nm}$ optical lithography. For higher resolution, shorter wavelength deep-uv irradiation is necessary. $\Lambda$ recent survey of Japanese electronics companies indicated that $50 \%$ of these memory device manufacturers were planning to use deep-uv lithography for $64 \mathrm{MB}$ DRAM. ${ }^{1}$ The other half will use $365 \mathrm{~nm}$ lithography in conjunction with phase shifted masks.

The standard diazonaphthoquinonc/novolac resists used at $36.5 \mathrm{~nm}$ are positive working resists which function on the basis of dissolution inhibition. The novolac polymers which are used for these applications have many desirable physical propertics including moderate dissolution rates in aqueous base solution, high optical transmission at $36.5 \mathrm{~nm}$, glass transition temperatures higher than $100^{\circ} \mathrm{C}$, and reasonable reactive ion etch resistance. ${ }^{2}$ However the application of novolac polymers in optical lithography is limited to wavelengths greater than 300 $\mathrm{nm}$ due to the high, unbleachable absorption at shorter wavelength. The efrect of high residual absorption has been predicted based on resist modeling to give rise to images with highly sloping side walls ${ }^{3}$ and this effect has been observed experimentally. ${ }^{4}$ The decp-uv optical properties of 
novolac polymers were improved by using p-cresol monomer ${ }^{5}$ but the lithographic performance of this polymer was limited because of a high dose requirement resulting from the need for nearly complete conversion of the dissolution inhibitor in order to develop the exposed film.

Poly(4-hydroxystyrene) (PIS) has considerably better optical properties at $248 \mathrm{~nm}$ than novolac as well as superior thermal properties and similar etch resistance. However the aqueous base dissolution rates of PHS films are faster than novolac by a factor of about ten. Higher dissolution rates, in general, lower the performance of dissolution inhibition type photoresists. Resist films comprised of diazonaphthoquinone in PHS show poor dissolution rate discrimination between exposed and unexposed film. ${ }^{6}$ However sulfonium salt dissolution inhibitors containing acid-labile sidegroups function very well lithographically in PHS. ${ }^{7}$

The aqueous base dissolution rates of PHS can be lowered by the incorporation of alkyl groups in the aromatic rings of PHS. Polymeric derivatives containing alkyl groups at the 3 and/or 5 positions have dissolution rates in aqueous base very similar to novolac. This modification makes the use of PHS more widely applicable for photorcsist applications which use dissolution inhibition. Furthermore this structural change does not adverscly affect the optical, thermal, and etch resistance properties of PHS.

\section{Experimental}

\section{Materials:}

Triphenylsulfonium hexafluoroantimonate (1) was prepared by a literature procedure. ${ }^{8}$ Dicarbonate (2) was prepared by reaction of bisphenol $A$ with di-t-butyldicarbonate. ${ }^{9}$ 3,5-dimethyl-4-t-butoxycarbonyloxystyrene (3) was prepared in two steps from commercially available 3,5-dimethyl-4-hydroxybenzaldehyde (4). 4-t-Butoxycarbonyloxystyrene (5) was prepared as described previously. ${ }^{10}$ The t-butoxycarbonyloxy (t-BOC) protected precursor copolymer (6) was prepared by radical polymerization of 3 and 5 in toluene solution with benzoylperoxide initiator. Phenolic copolymer (7) was formed by heating a chloroform solution of 6 with trifluoroacetic acid.

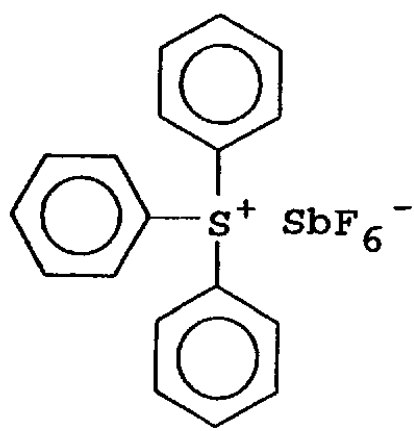

1

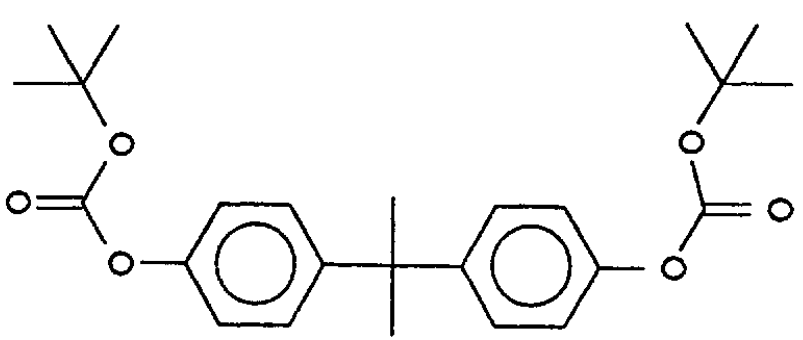

2 
<smiles>Cc1cc(C=O)cc(C)c1O</smiles>

4
1) $(\text { ( BuOCO })_{2} \mathrm{O}$

2) $\mathrm{CH}_{2} \mathrm{PPh}_{3}$<smiles>Cc1cccc(C)c1OC(=O)OC(C)(C)C</smiles>

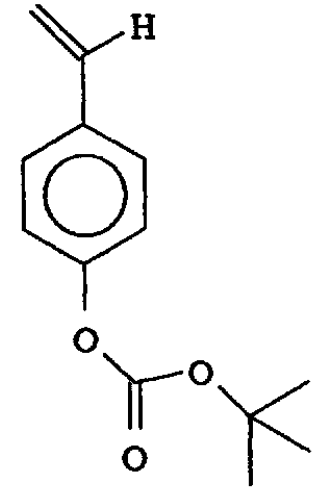

5

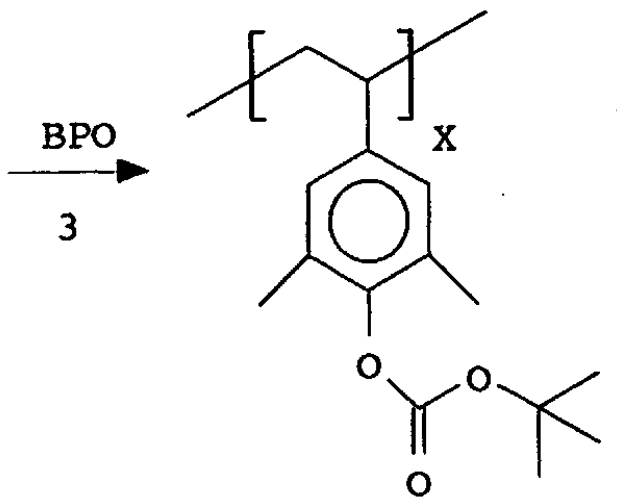

6
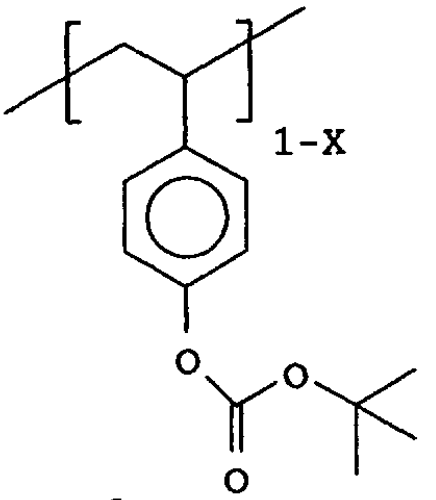

$\downarrow \mathrm{H}^{+}$<smiles>[X]C(C)C(CC(C)(C)C)c1cc(C)c(C)c(C)c1</smiles>

$\mathrm{OH}$

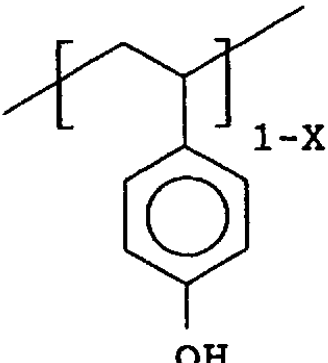

7

Scheme 1. Preparation of 3,5-dimethyl PIIS derivatives 


\section{Measurements:}

III and ${ }^{13} \mathrm{C}$ NMR analyses were performed on an IBM instruments $\triangle \mathrm{F} 250$ spectrometer. Ultraviolet spectra were recorded on a Hewlett-Packard Model 8450^ UV/Visible Spectrometer. Thermal analyses were done on a DuPont DSC 1090 instrument. Molecular weights were determined on a Waters Model 150C Liquid/Gel Permeation Chromatograph with refractive index detector (polystyrene standards). Dissolution kineties were determined from rate data generated on a Perkin Elmer Developmental Rate Monitor Model 5900.

\section{Lithographic Evaluation:}

Films were prepared by spin coating of filtered solutions. A postapply bake was performed at $90^{\circ} \mathrm{C}$ for 5 minutes on a hot plate. Exposure was performed followed by postexposure bake on a hot plate. Contact optical exposures were performed on an Optical $\Lambda$ ssociates $30 / 5$ Exposure Tool through $254 \mathrm{~nm}$ band pass filters. Projection printing was done with a Perkin Elmer 500 Micralign Exposure System with a $300 \mathrm{~nm}$ band pass filter or with an Ultratech X248E deep-uv stepper. Post exposure bake was done at $70-90^{\circ} \mathrm{C}$ for 90 scconds. Development was performed by immersion in a rapidly stirred developer solution.

\section{Results and Discussion}

\section{Preparation of alkylated PHS derivatives}

The effect of alkyl substituents was evaluated by a modeling program which was used to compute aqueous hydration energy. The results of these calculations showed that alkyl substituents at the 3 and 5 positions of poly(4-hydroxystyrene) significantly affect the hydration energy and would be expected to lower the dissolution rates of the resin with aqueous base.

The 3,5-dimethyl PIS copolymers 7 werc synthesized as shown in Scheme 1. The dimethyl monomer (3) was prepared by reaction of benzaldehyde derivative 4 with di-t-butyldicarbonate followed by reaction with the methylene Wittig reagent. Radical copolymerization of 3 and 5 gave a random copolymer whose composition varied only slightly from the feed ratio. The removal of $\mathrm{t}-\mathrm{BOC}$ functionality was performed by heating with trinuoroacetic acid.

\section{Polymer properties}

The copolymers were analyzed by 'II NMR to determine the composition. For a serics of varying compositions of copolymer 7 , the mole fraction of dimethyl component in the copolymer (X) was nearly equal to the mole fraction in the feed.

The glass transition temperatures for copolymers 6 and 7 were measured by DSC analysis. For the t-BOC protected copolymer 6 an increase in the molc fraction of the methylated component lead to a slight increase in the glass transition tempcraturc. For the phenolic copolymer 7 , however, increases in the methylated component resulted in a decreased $T_{g}$ (Table 1). 


\begin{tabular}{|c|c|c|}
\hline \multirow{2}{*}{$X$} & $T_{g}$ (DEG C) \\
\cline { 2 - 3 } & COPOLYMER 6 & COPOLYMER 7 \\
\hline 0 & 129 & 188 \\
\hline .25 & & 182 \\
\hline .40 & 127 & 179 \\
\hline .60 & 133 & 175 \\
\hline .75 & 135 & 172 \\
\hline 1.0 & & 159 \\
\hline
\end{tabular}

Table 1. Glass transition temperatures for copolymers 6 and 7

As expected from model studies, the dissolution rates of these copolymers is strongly dependent on copolymer composition. The dissolution rate in $0.27 \mathrm{~N}$ potassium hydroxide solution was measured using a dissolution rate monitor and is shown in Figure 1 plotted versus the mole fraction of the dialkyl substituted component (X). Increasing $\mathrm{X}$ dramatically decreases the dissolution rate. Copolymer with $\mathrm{X}=0.4$ has a dissolution rate which is an order of magnitude less than PHS and thus in the same range as novolac. Material with $\mathrm{X}$ in the range 0.4-0.5 was most useful for lithographic applications.

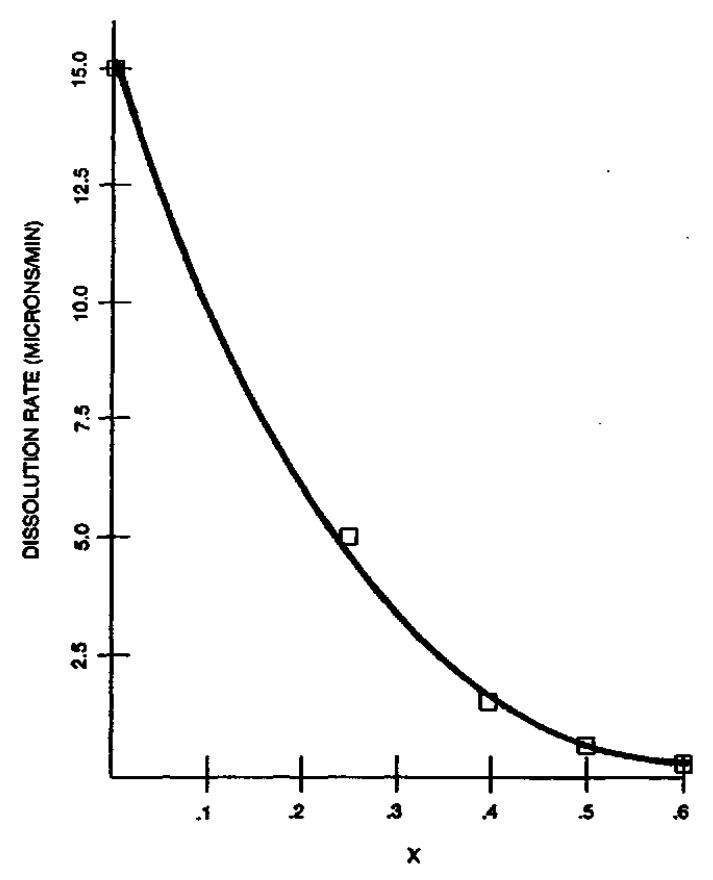

Figure 1. Effect of copolymer composition on the dissolution rates with $0.27 \mathrm{~N} \mathrm{KOH}$ solution. 
The ultraviolet absorbance was measured for the copolymers 7 . $\Lambda$ s expected, incorporation of the methyl substituents had little effect on the PHS deep-uv optical properties. Novolac film is also shown for comparison (Table 2). The absorbance of the copolymer at 248 and $254 \mathrm{~nm}$ is significantly improved relative to novolac and is low enough to make this material applicable for deep-uv photoresists.

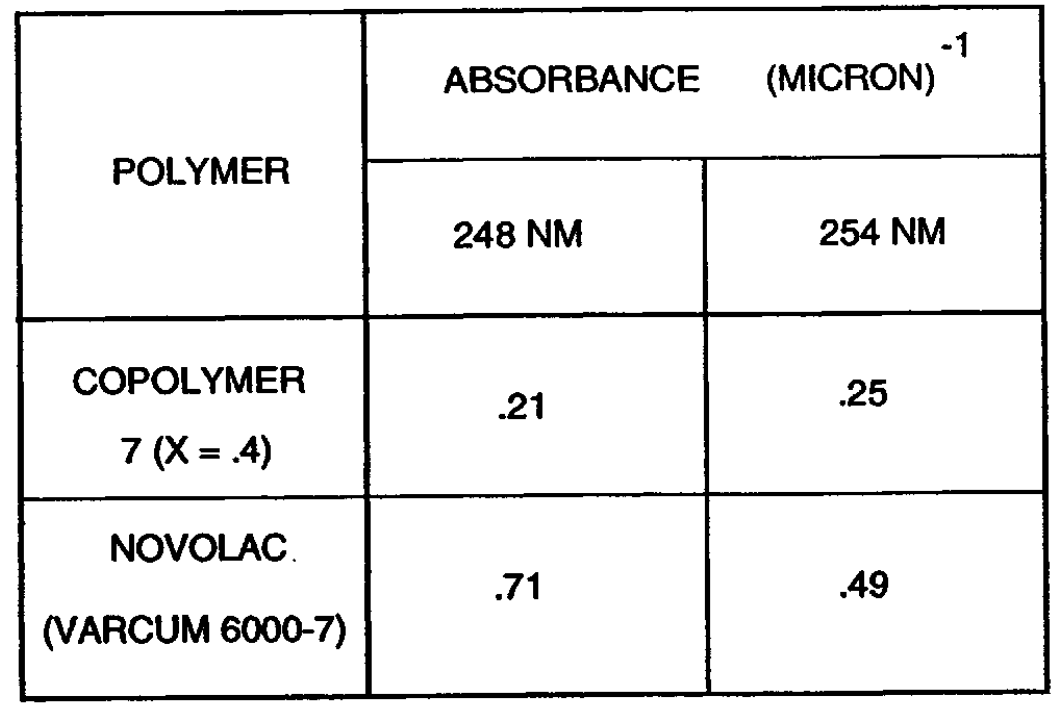

Table 2. Absorbance value for 7 and novolac at deep-uv wavelengths.

The etch resistance of these materials was evaluated and compared with novolac resin. The films were etched using a reactive ion etcher with an oxygen plasma. The etch rates of the copolymer 7 was found to be similar to that of novolac.

\section{Lithographic properties}

When formulated with a diazonaphthoquinonc derivative (4-cumylphenyl ester of 2-diazo-1-naphthoquinone-4-sulfonic acid) and exposed with near-uv radiation, alkylated PHS derivatives function in a fashion similar to DNQ/novolac resists. Film dissolution studies were carried out by quartz crystal microbalance (qcm) analysis. ${ }^{\prime \prime}$ The resist films show typical positive photoresist behavior, i. e. increases in dissolution rate with increasing exposure. No induction period (delay before the onset of development) was observed. Images wcre obtained by projection printing with a $300 \mathrm{~nm}$ filter on a Perkin-Elmer 500 exposurc tool. The images (Figure 2) show nearly vertical wall profiles for 1.25 micrometer $(\mu \mathrm{m})$ dimension features.

DNQ sensitizers are not well suited for application at deep-uv wavelengths because the photoproducts are not transparent in this region. However other classes of diazo compounds do photobleach in the deep-uv region and have bcen applied as dcep-uv photorcsist sensitizers. One such class is the diazopiperidinedione sensitizers which have been successfully imaged when combined with novolac resin. ${ }^{12}$ The contrast of this binary resist system is quite poor $(y=1.3)$ due to a combination of resin absorbance and poor selectivity of the photoproduct toward reaction with phenolic resin. 


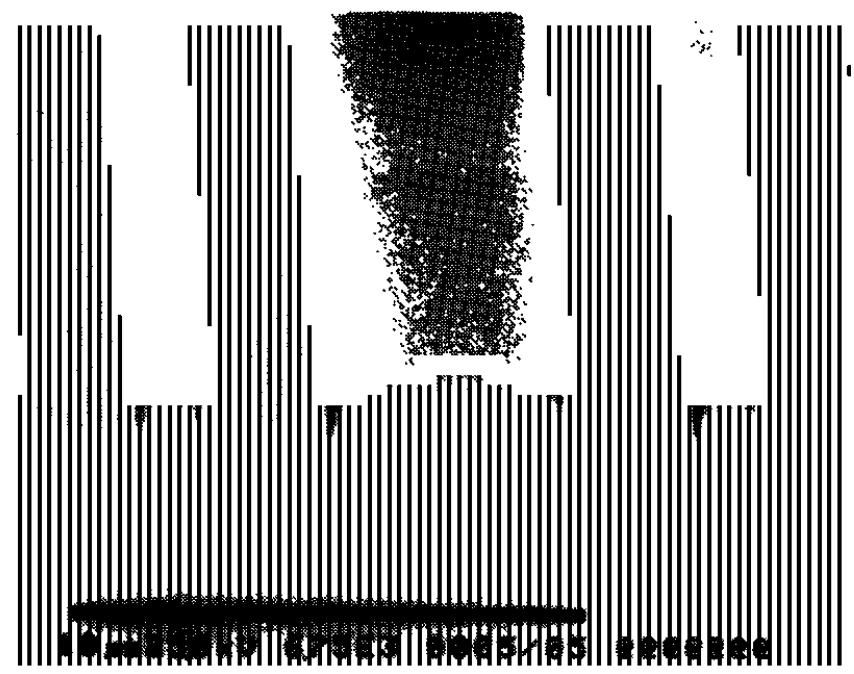

Figure 2. SEM micrographs of 1.25 micron features obtained from exposure of DNQ/7 films.

Binary resists prepared from diazopiperidinediones and alkylated PIIS derivatives were evaluated as deep-uv resists. The resist films showed positive resist characteristics with contrast $(\gamma=1.6)$ slightly improved relative to the novolac version of the same resist. Projection printed images show highly rounded image profiles. Low contrast for this resist system is most likely due to an undesirable side reaction between the diazopiperidinedione photoproduct and the resin.

The use of acid sensitive dissolution inhibitors was also explored. These are three component resist systems containing phenolic resin, acid photogenerator 1 , and acid-sensitive dissolution inhibitor 2. This resist system (BPABOC) was investigated previously using novolac as the phenolic polymer ${ }^{13}$ and found to be a highly sensitive positive deep-uv photoresist. However the contrast $(\gamma=1.8)$ was low due to novolac absorption and as a result the image wall profiles were sloping and resolution was limited.

BPABOC was reinvestigated using alkylated PIS derivatives and found to be significantly improved relative to the novolac version. The sensitivity of $B P \Lambda B O C$ was less than $5 \mathrm{~mJ} / \mathrm{cm}^{2}$ and the contrast was greater than 3.0. Film dissolution rates were analyzed by $\mathrm{qcm}$ and significant induction effects were observed for unexposed and lightly cxposed films. The significantly higher contrast for BPABOC in alkylated PHS is likely due to a combination of inductive effects and superior transmittance for the resin. Projection printed images of BPABOC in alkylated PIIS have improved sidewall profiles as expected for higher contrast materials. Submicron resolution has been achieved using an Ultratech decp-uv stepper (Ultrastep X-248E) and 0.7 micron fcatures are shown in Figure 3.

A comparison of dissolution rates was carried out for BPABOC rcsists formulated in four different resins systems. In all cases the composition of the resist was maintained at $12.5 \% 2$, $4 \% 1$, and $83.5 \%$ phenolic resin. The phenolic polymers which were investigated include copolymers of 3-ethyl-4-hydroxy-styrene and 4-hydroxystyrenc, a copolymer of styrene and 4-hydroxystyrene, and novolac. The results show (Table 3) that the best dissolution rate 


\section{J. Photopolym. Sci. Technol., Vol.5, No.1, 1992}

discrimination was obtained for the ethylhydroxystyrene copolymer containing $40 \%$ of the ethyl monomer unit.

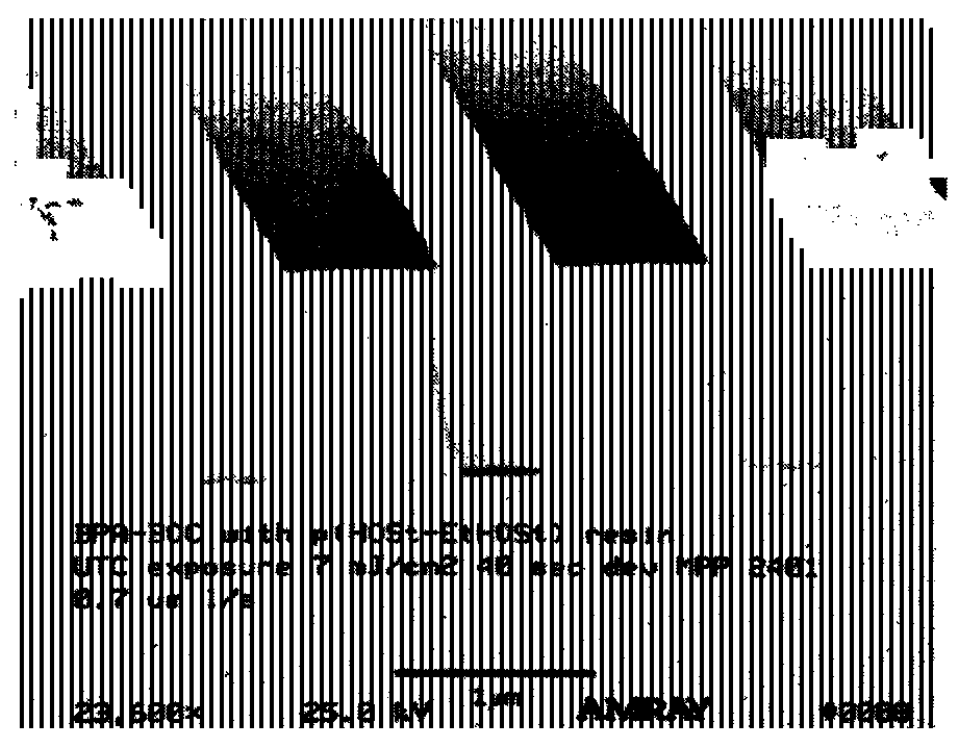

Figure 3. SEM micrographs of 0.7 micron features obtained from exposure of BPABOC in alkylated PHS polymer on an Ultratech X-248E deep-uv stepper.

\begin{tabular}{|c|c|c|c|}
\hline POLYMER & $\begin{array}{c}R \\
\text { (MICRON/M) }\end{array}$ & $\begin{array}{c}\mathrm{R}_{\mathrm{O}} \\
\text { (MICRON/M) }\end{array}$ & $\mathrm{R}_{\mathrm{R}}$ \\
\hline ST/HS & .88 & .27 & 3.2 \\
\hline $\begin{array}{c}\text { EtHS/HS } \\
(\mathrm{X}=0.6)\end{array}$ & 1.5 & .020 & 73 \\
\hline $\begin{array}{c}\text { EtHS/HS } \\
(\mathrm{X}=0.4)\end{array}$ & 1.3 & $<.01$ & $>200$ \\
\hline NOVOLAC & .91 & .021 & 43 \\
\hline
\end{tabular}

Table 3. Comparison of dissolution rates for BPABOC resist formulated in various phenolic resins. 


\section{Conclusions}

Alkylated poly(4-hydroxystyrene) derivatives have been prepared and evaluated for deep-uv lithography applications. The copolymers showed a wide range of dissolution rates in aqueous base and, by proper choice of copolymer composition, dissolution rates identical with novolac resins can be obtained. The combination of lower dissolution rates and superior optical properties makes these materials attractive for use in dissolution inhibition resist schemes. Both binary resists using diazonaphthoquinone and three component acid-catalyzed resist perform well lithographically in these resins.

\section{Acknowledgment}

The authors wish to acknowledge Ralph Dammel of Hoechst $\Lambda \mathrm{G}$ for providing samples of the monoalkylated PHS copolymers.

\section{References}

1. P. Burggraaf Semiconductor International, (February, 1992) 42.

2. T. R. Pampalone Solid State Technol., 27 (1984) 115.

3. B. D. Grant, N. J. Clecak, R. J. Twieg, and C. G. Willson IEEE Trans. Electron Devices, ED-28 (1981) 1300.

4. V. Pol Solid State Technol., 30 (1987) 71.

5. E. Gipstein, A. C. Ouano, and T. Tompkins J. Electrochem. Soc., 129 (1982) 201.

6. M. J. Hanrahan and K. S. Hollis Proc. SPIE 771 (1987) 128.

7. R. Schwalm Proc.ACS Div. Polym. Sci. Engr., 61 (1989) 278.

8. J. M. J. Fréchet, E. Eichler, H. Ito, and C. G. Willson Polymer, 24 (1983) 995.

9. J. V. Crivello and J. H. W. Lam J. Org. Chem., 43 (1978) 3055.

10. F. Houlihan, F. Bouchard, J. M. J. Fréchet and C. G. Willson Can. J. Chem., 63 (1985) 153.

11. W. D. Hinsberg, C. G. Willson, and K. K. Kanazawa, J. Electrochem. Soc., 133 (1986) 1448.

12. C. G. Willson, R. D. Miller, D. R. McKean, L. A. Pederson, and M. Regitz, Proc. SPIE 771 (1987) 2.

13. D. R. McKean, S. A. MacDonald, N. J. Clecak, and C. (i. Willson Proc. SPIE 920 (1988) 60 and references cited therein. 